recommended the legs to be wrapped in flannel soaked in treacle for some days, which procured him complete relief. He therefore thought there was sone sedative infuence in the treacle.

Fracture of the Clavicle.-On the 10th of June, 1846, Mr. F. Bulley stated that he had under his charge in the Hospital, a man, whose clavicle had been fractured in the effort of wowing. The fracture was situated near the acromial process. There was bat slight displacement. The fractured bone was kept in situ, by a strong buffalo-leather splint, covered with adhesive plaster, and bound down by straps of emplastrum roborans, which, with a pad in the axilla, and the arms bound to the side, he generally finds successful. Mr. Bulley, also uses this leather in cases of fracture of the radius near the wrist with-great advantage.

Dr. Bradshaw remarked that the leather splints possessed an advantage over those made with pasteboard, in not occasioning that irritation of the skin which was frequently produced by the latter, owing to the pitch or tar contained in them.

Hernia of the Stomach.-At the same meeting Mr. Harrinson presented to the Society a rough cast of the npper portion of the abdomen of a man, whose case he thus related:-While walking along the street the man was seized with a violent rigor and such excessive pain that he fell to the ground He had, however, recovered before $\mathrm{Mr}$. Harrinson got to him. The cause of his sufferings remained unexplained for three or four days, when Mr. Harrinson discovered a small tumour in the upper part of the abdomen, to the left of the left rectus muscle, which disappeared on pressure, and dilated on coughing. It appeared to be hernia of the stomach, for if it were the colon, it would hardly have produced so great an amount of suffering. It did not require any treatment beyond the mechanical support of a truss to prevent it from protruding, and it was chiefly with a view to inquire what apparatus was best adapted for the purpose, that Mr. Harrinson brouglit the case forward,

Mr. F. Bulley stated that there was an apparatus, invented by Wciss, consisting of a circle of ivory adjusted by a spring and a belt, for umbilical hernia, which he t'lought might suit this case.

\section{IX.-Diseases of THE SKIN.}

Allinoism.-On the 30th of September, 1846, your reporter exhibited to the Society three femule children from Padirorth who are albinos, of the respective ages of seven and five years, and of nine months. The complexion of the father was brown, and the mother dark. The eldest boy, nine years of age, was of the same brown complexion as bis father, and so was the second boy, three years of age. The two elder girls were unable to bear the light of the sun, and could only see objects when very close to the eye. The mother had borne six children; her first-born, a female, was likewise an albino, and died at the age of four days. The three surviving girls were very liable to bowel complaints.

X.-Statistics.

On the second of September, 1846,. Mr. May read a statistical table of the cases of death which had occurred in his practice between August, 1845, and August, 1846, in which the modes of death are arranged in the order in which they occurred,-as apncea, asthenia, coma, \&c. This table has already appeared in the Medical Gazette, and is therefore probably familiar to you all.

I have now, gentlemen, gone through all the cases which have come under our notice during the past year. You will, I trust, agree with me in thinking that many of them possess great interest; and should their recapitulation have proved wearisome to you on the present occasion, the blame, I fear, attaches to your reporter. If to some I may have appeared too prolix, the best apology I can offer you is the anxiety I bave felt to do full justice to every member of the Society.

The great length to which this address has extended will prove that we have not had to complain of any lack of materials for discussion since our last anniversary; still we cannot but remark that we have mainly depended upon the presentation of morbid specimens, and that independently of those specimens, very few papers have been read during the past year. Now, though $I$ by no means wish to detract from the interest and instruction which is to be fonnd in the recital of cases which have terminated fatally, and in the examination of the organic changes which have resulted from disease, still there is an equally important class of disorders, which do not ordinarily go on to a fatal termination, and of which we never have the opportunity of examining the morbid alterations upon this table. Such disorders at present seldom come under our notice; and yet no one can doubt that in a practical point of view, it is of much more ralue to the practitioner to treat successfully the curable diseases, than to be learned in the pathology of those which are unfortunately incurable. I would therefore renture to suggest that some means be adopted for securing at each of our meetings the reading of a paper, and $I$ feel assured that no member will decline to take his turn, which cannot come more than unce a year.

In conclusion, Gentlemen, it only remains for me to thank you for the patience with which you have listened to this, I fear too lengthy, address, and to express a hope that each succetding year may produce a reporter more wortiy of your Society.

\section{ON FUNCTIONAL DISORDER OF THE LIVER.}

By Robert Hutchinson Powerr, M.D., Tunbridge Wells.

(Read at the Annual Meeting of the South-Eastern Branch of the Provincial Medical and Surgical Assuciation, held at Reigate, June 30th, 1847.)

It is proposed in this paper to notice briefly some of the more frequent causes and modes of actions, with the principles of treatment pertaining to, certain functional derangements of the hepatic system; but the limits within which I am necescarily confined, will prevent 
any attempt at division into distinct heads. In my remarks I would merely indicate those dynamical affections commonly known as "bilious complaints," ariving, 80 far as the the liver is in fault, most probably from increased and deranged excretion, and a slightly vitiated condition of the bile, being seemingly produced by those norbific influences subsequently to be mentioned. Such inquiries will not be deemed obtrusive, when we recollect the frequency of biliary disorder in this-so to speak-age of bile, and the daily reference made to medical men for explanation of, and relief from, its due concomitants, which, from this continued discomfort, make every-day existence far from tranquil. We shall take a rapid glance at the anatounical and physiological relations of the liver.

The intimate anatomical structure of the liver is by no means satisfactorily determined, notwithstanding the minute attention bestowed on it. I shall not pause to describe the most recent statersents, but merely remark that it may be considered the largest glandular organ in the frame, supplied with a numerous and complicated vascular apparatus, and nerrous fibrils; and the secreting structure being arranged in lobules, the aggregate acini, \&c., endowed with functions highly important to the animal economy. It will be of consequence to bear in mind the anatomical relations of the liver, especially of its ducts, to adjoining viscera, as from these will be found to arise many sources of bilinry derangement.

The profession are doubtless aware of the modern notions held by physiologists as to the functions performed by the liver, and the uses of the biliary secretion to the economy. Of these the most important are said to be the production of a secretion indispensable to life. Recent and numerous experiments by Schwann have incontestibly proved this, although contrary opinions have been advanced by others. The immediate end subserved appears to be,-the abstraction from the blood of a fluid taking an important part in digestion and respiration, and the expulsion from the system of the debris of its tissues; its chief constituent being an organic compound, consisting, according to Dumas, of carbon, $63.5,+$ bydrogen $9 \cdot 5$, + nitrogen 3.3 , oxygen and sulphur, 23.9 ; the last constituent being a non-oxidized body, goes far to prove its important office in respiration.

Chemists of the highest repute differ with respect to this compound; Berzelius maintains it to be bilin, a neutral body united with soda, probably like albumen; Gmelin, biliary sugar; Thenard, picromel a resinous substance; Liebig and Demarçay conceive it to be an oily acid-the choleic, united with soda. The diserepancies seem to arise from the latter authorities neglecting to examine recent bile, as pointed out by Berrelius, decomposition occurring with facility. - Cloletic acid is readily decomposed by rariows re-agents, weide sind altialie giving rive to net compounds, hence probably the difference of opinion as to the reul constitution of the bile. It consists, according to Berzelius, of about $\tau \frac{1}{2}$ per cent. of solid matter, in the proportion of,-bilin 5.0 ; chloride of sodium, lactate of soda and alcoholic extractive matter 1.5 ; alkaline sulphates, phosphates, with extractive, insoluble in alcohol 0.43 ; mucus and cholesterine 0.20 ; watermaking up the remainder.

According to Schultz, the quantity of bile secreted is considerable, but its exact amount hrs not been determined. Disease appears to alter its composition remarkably, the solid constituents being doubled, the fat and colouring matter undergoing the most remarkable increase, the saline ingredients being diminished. The bile appears, according to the researches of Boucbardat, to aid digestion only by furnishing soda for the saponification of the fatty ingesta; but Platner conceives this to be quite secondary and subsidiary to the liberation of bilifellinic acid, which combines with the elements of food, thereby preventing that decomposition and loss of its nutritive properties, which, he asserts, would otherwise ensue. The:e conclusions need confirmation. The effect of bile in augmenting the peristaltic action of the intestines is well known,-an effect probably induced by its saline constituents, as, except the colouring matter, the other biliary ingredents are found in health to hare disappeared from the fæces when chemically examined; this disappearance, although contrary to the commonly receired notions, clearly proves the important and necessary office subserved by certain constituents of the biliary fluid in respiration. The excrements of serpents being but slightly coloured would seem to confirm this view. We shall now revert to the more immediate object of this paper.

The popular opinion with respect to the frequency of biliary disorder, as arising from indigestion, is certainly well founded; the operations ensuing on the introduction of ingesta into the alimentary canal, are so intimately related, both anatomically and physiologically, with the liver, as to render the communication of deranged action from the former to the latter highly probable. In fact, disorder in one organ cannot long continue without implicating others, such is the beautiful harmony existing in the human mechanism. Indigestion, as resulting from biliary disorder, is likewise observed in the present instance; it shall be our care to search out the functional derangement first causing deviation from healthy action; and, at the same time, that regard is had to the several functions, to direct our special attention to that aberration first in order, if such can be traced. The difficulty of drawing a line of demarcation between gastric and hepatic derangement is, very likely, the reason why both states have been considered together by many gystematic writers; for practical reasons, however, both will require separate consideration in the majority 
of dyspeptic or bilious complaints. The functional derangement forming the subject of this paper, is probably attended by an increased and sonewhat altered biliary secretion, the excretion of which is both retarded, and in part infletted, from it usual course. The experiments of Dr. Beuumont, who found regurgitation of bile into the stomach under certain circumstances to which we will revert,-the sweet taste experienced in the fauces, very likely arising from the presence of glycynin in the blood, which is excreted from the buccal mucous nembrane on such occasions,- the constipation usually attending,as well as the insalivation, acidity, nausea, and ejection of bile "by romiting, go far towards establishing this conclusion. Prenising thus far, we proceed to investigate the causes and nature of this departure from healthy action in the liver.

That the food ingested exerts a marked influence over the bile, is a matter of commun observation; lean animal fibre seems least likely to tax unduly the biliary function; all carbo-hydrogen substances, alcoholic liquids, and fat in particular, eridently cause an increased secretion of bile. The total amount of food, if used in excess, may likewise have a similar effect, either from the presence of those articles of food just mentioned, or from the morbid erythisra set up in the stomach and duodenum, which, being propagated to the biliary apparatus, causes misdirection of its proper secretion, at the same time that its elements exist in the blood in unusual quantity. The anti-peristaltic action of the bowels is probably but a sequel and symptom of this state of things; confined bowels, at first an effect, subsequently becomes a seeondary cause of, derangement. But adverting to the less-recognized or more obscure causes of biliary derangement, repeated observation has led me to attribute, in many cases, its production to atmospheric infuence-a cause familiar to most persons, but the manner of its operation not being sufficiently understood. A predisposition to be affected from this source, whether congenital or acquired, is incrcased by the nervo-bilious, known as the choleric temperament, which renders the individual of this conformation very susceptible to all atmospheric changes. Life being beyond certain limits, antaronistic to external forces, its relative activity will determine the amount of resistance of the vital powers to those agencies. Changes of temperature, its excess or diminution, by depressing the nervous influences, are well-known causes of biliary disorder. Heat also acts on the liver by checking respiration, and consequently, the carbonic acid exbaled, thereby compelling other organs to take on supplementary action, the liver being the principal emunctory. Cold, if not intense, and if unaccompanied with humidity, does not seem to have much tendency to overload the hepatic ressels; rather otherwise, especially from respiration being rendered more active. But atmospheric bomidity, particularly when uncombined with the air, must have a noxious influence, either by checking excretion and exhalation from the skin and lungs, or by resolving it: agency into that of the attendant negatively electric condition of the atmosphere, which operates more readily on the system when the air is surcharged with moisture. Moreover, heat and cold are invariably attended with, if not caused by, a change in the electrical state of that medium "in which we live, and move, and hare our being," and probably best exprese this, its agency on the system : when + (plus) the nervous and vascular system acting well,-cateris paribius; when - (minus) all the functions of the frame become torpid, the liver being peculiarly liable to inaction from its size, situation, and vascularity. There can be no doubt that much remains to be determined under this Lead, and principles of treatment constructed with reference to its important bearing on vital action. The electrical state of the atmosphere influences the bepatic circulation, primarily or directly, by diminishing nervous action generally; and indirectly, by inducing barometrical states of the air effecting inadequate pressure on the surface.

Now, in the disordet under consideration, the quantity of bile secreted seems to be angnented, obstruction of the systemic circulation seemingly favouring this by retarding the mass of blood passing through the portal vessels, thus determining a relative increase of electrical influence.

Closely related to the electric condition of the atmosphere, is its magnetic state; this must exert an importani influence on the frame, as there are the best reasons for attributing all its changes to chemical action, the result of its polarity, or generally of its magnetic properties. The electro-magnetic force, which appears to produce increased biliary secretion from the liver, seems likewise to determine a similar result in the stomach of its normal acid secretion,-the liver representing the negative, the stomach the positive, pole. We find this view explanatory of the increased secretion of acid constantly attending biliary disorders, to which we shall presently advert. The magnetic currents accompanying certain winds may also strongly affect the system; the liver, from its size and office, giving most evident tokens of its disturbance. Again, lunar infuence probably alters the magnetic state of the atmosphere which rests on the animal fabric. Cloudy weather, notoriously a cause of biliary derangement, is compounded of many agencies in relation to the system; but its concomitant electro-magnetic conditions, produced in part by the interruption of light, are the most important.

Another very frequent cause of biliary disorder arises from deranged nutrition, whereby the motive powrers are diminished and digestion interfered with; 
disturbance and mis-direction of biliary secretion ensuing in consequence. Of this more anon. Allied to the noxious influence of beat, neglect of exercise may be mentioned. Sleep, especially in autumn, acts in the same wry,-namely, by unduly taxing the biliary function, consequent to cbecked respiration. Depressing passions probably act in a similar manner; as do mental emotions generally.

The last source of biliary derangement which I shall potice is gastric irritation. This state being constantly accompanied with acidity of the stomach, solicits or diverts the flow of bile to it. The recent experiments of M. Bernard, confirm those of Dr. Beaumont, as to this occurrence. Here we see a beautiful provision of Nature frustrated, and running into an abnormal process; for although intended to neutralize the free acid of the stomacb, it sets up further irritation, and renders its contents indigestible. Platner has shown that when bile fiows into the stomacb, double decomposition ensues, its soda uniting with the gastric acid; the acid with which the soda was previously united, forming with bilin bilifellinic acid, which combines with the proteine compounds present, rendering them indigestible, and consequently, a source of continued disturbance. Pepsin, the organic principle of the gastric juice, is rendered inert in the same manner, and by neutralizing the free acid of the stomach, it loses its digestive properties, on albuminous matter. This obtains, according to the latter experiment, more particularly if bile be present at the commencement of digestion. In fact, morbid sensibility of the gastric mucous membrane, however induced, will solicit a flow of bile into the stomach.

The immediate effect and mode of operation of all these causes may be referred to regurgitant bile in the stomach; bence, after effecting abnormal changes, the remainder is absorbed into the torrent of the circulation,-effects greatly aggravating, if not giving rise to, the characteristic symptoms of bilious complaint, headache, nausea, deranged secretions, coldness, and general nervous depression. But the essential nature or point of departure from healthy action in the frame would seem, from the above facts, to originate in a lesion of the nervous system; bence, retarded circulation and abnormal secretion; the liver, from its peculiarities specially feeling this noxious influence, and directly producing the characteristic state. These progressive changes are in some measure illustrated in sea-sickness, in which the characteristic symptoms run as it were rapidly into each other, and quickly subside on removal of the exciting cause.

The preceding investigation will serve to direct our principles of treatment, which will have reference to the functions performed by the biliary secretion in the economy, - namely, a provision for eliminating from the blood effete tissues consumed in the lungs;-a flaid vicarious of the products of respiration, or of other functions when cbecked or deficient; - a necessary. element in the digestion of certain alimentary principles;-and a means of sustaining the peristaltic action of the intestines.

1. A locality in which a temperate, dry, moderatelydense, and equable atmosphere obtains, will have an excellent effect in aiding other remedial measures. I have found the climate of Tunbridge Wells highly beneficial in such cases; and I mention this therapeutio indication thus early, feeling sure that the best directed treatment will not unfrequentiy fail, if the physical characters of the air in which the person resides exhibit those noxious conditious previously noticed.

2. A careful regulation of diet, subtracting as much as possible alcholic, fatty, saccharine, and amylaceous ingesta; perhaps of the latter, well fermented or gluten bread, well-boiled rice, and tender fresh vegetables in small quantity, are the least objectionable; lean and tender animal food in moderation, weak black tea, and milk, if it agree, twice caily; a small quantity of pale sherry if the vital powers be much reduced, otherwise, pure soft water; - these are most suitable. It will be understood that the proteine compounds are least likely to furnish pabulum for biliary fluid, or to tax the hepatic system.

3. The observance of such a regimen will go far to remove another pathological condition often present,namely, gastro-intestinal irritation, which, as we know, is a fruitful source of biliary disorder; gentle friction, dry cupping over the abdonen, and the occasional application of mustard cataplasins, will be useful auxiliaries. Moderate exercise, especially on horseback, will prove highly useful by unloading the abdominal venous system. Tepid shower bathings, with brisk friction over the abdomen, will be advantageous; the surface should be well protected by flannel or cotton fabric. Regularity as to time of meals, and as to the length of sleep, in a well-ventilated room, not exceeding eight hours, with a tranquil state of mind, will powerfully co-operate with other means to restore the tone of the system, and the healthy action of the secreting organs.

4. I have little to say respecting medicinal remedies, such being well known to iny audience. I may remark, however, that a reliance should be placed on hygienic rather than upon pharmaceutical measures, the former alone bringing about permanent improvement. Mercurials, though giving temporary relief, ultimately act iujuriously if long continued, by depressing the system. Hydrargyrum cum Creta, and Extr. Hyoscyamus, given sparingly, will unload the abdominal veins, and correct vitiated secretion, these being combined with, and followed.by, light vegetable tonics, - as rhubarb, hop, calumba, with alkaline, curbonates, and saline aperients. Drastic purgatives must be carefully shunned. The gastric intestinal mucous membrane is generally very sensitive in such cases, and will not tolerate minerah 
or even the more active regetable tonics, at first; subsequently, bowever, chalybeates will produce an excellent effect, if this irritation be first subdued, and if combined with alkaline aperients. A suitable mineral water will often prove highly useful, -as the artificial Vichy, or Ems, or saline Cheltenham water, followed by a course of Tunbridge chalybeate. From the introduction of aerrated chalybeate water here, at my rocommendation, a most efficacious and agreeable remed may be now had, a course of which will be attended with much benefit, if preceded by appropriate treatment.

The carbonic acid with which this aërated water is -surcharged, is in itself a highly useful remedy, its reception into the stomach being followed by agreeable and exhilirating sensations. From its stimulant impreszion on the organic nerves, distributed over the mucous coat, it increases the secretion of gastric juice. Its effects, when received into the blood are analogous to those arising from the vegetable acids. Finally, carbonic acid evidently entrances the tonic properties of the chalybeate."

In conclusion, I would just remark, that in biliary disorders, as in all others, we must seek for the pathological cause, and counteract its influence, if we look for success, - a result, moreover, to be further solicited by restoring all the functions to full and barmonious action.

\section{PERIODICAL PURPURA VICARIOUS OF THE CATAMENIA.}

By Chardes Bargam, M.D., Truro, Physician to the Royal Cornwall Infirmary.

(Read at the Annual Meeting of the South-Western Branch of the Provincial Medical and Surgical Associat:on, held at Truro, July 28th, 18i7.)

Ann Teague, aged 17, was admitted into the Cornwall Infirnary under my care, November 12th, 1846. She is rather tall, well formed, witb dark hair and eyes, and a pale exsanguine countenance. She has always had sufficient food and clothing, and has been only einployed in household work. Her father and mother are living, and she has six brothers, and one sister, fire years old. They are all in good liealth. With the exception of the ordinary diseases of childloood, which she passed through very favourab!y, she had no illness, but always considered berself well and strong till about two years ago; she was then seized suddenly with a severe pair. in the right side, just below the ribs. She was attended by a medical man, and in about a month the pain left ber. About two months after this she expectorated, without cough, some dark-coloured blood, and fancied it came from the throat. The bleeding recurred for a few days only, and was not attended by pain in the side. About th:ee months later ber nose bled profusely, she thinks more than a quart, and she was so much weakened as to be confined to her bed. The mother was alarmed, und resorted to a celebrated 'charmer.' The old woman did not visit the daughter, but merely took down ber name on a piece of paper, over which she performed a sort of incantation, and then pronounced the bleeding to be stopped. This the mother found on her return to be the case; but on the evening of the same day the patient was covered with purple spots, the largest about the size of a pea. Her medical attendant was again summoned, and at the end of a week the spots disappeared. She soon. felt quite well again, but precisely one month from her last illness the body became again corered with a similar eruption; the spitting of blood returned with it, and the inside of her mouth, the whole surface of the tongue and palate, was covered with dark spots. The gums bled on the slightest touch, and eating and ewatlowing became very painful. The bleeding continued for a week, but it was a fortnight before the mouth was well and free from spots. After the lapse of another month, to the rery day, precisely the same symptoms occurred; and up to the date of her:admission, the bleeding from the mouth had returned, with extraordinary precision, every montl. It began on a Priday, and it last appeared on a Sunday, having varied only these three days in about a twelvemonth. She states the quantity of blood to be about the same on each occasion, and that its discharge continues one week, the mouth getting well after another week. There has been one exception to the uniforinity of these periodical symptoms. About six months ago, on the day the hæmorrhage from the mouth was expected, a sanguineous vaginal discharge occurred; this increased the next day, and lasted for a fortnight. There was no bleeding from the mouth, neither was it sore, but the spots made their appearance, although of a lighter colour, and less numerous on the body.

On her admittance she made no complaint; the functions geuerally were healthily performed, and ber condition merely indicated a degree of anæmia. The tongue was very pale and flabby; both its upper and under surfaces, together with the gums and inside of the cheeks, presented the sume exsanguineous appearance.

The return of bleeding froin the mouth was expected. on the 22nd, and on that day the tongue had lost its pasty appearance, and had become redder, and more natural. Sine complained of violent pain across the loins.

On the 25th she awoke with a nasty taste in her mouth, and the saliva was tinged with blood. She aiso noticed spots over the cliest and arms. These had increased in number and size at the time of the visit, (9 a.m.,) and the sputa then consisted entirely of dark blood. 'This formed a coagulum, if the mouth was not frequently cleared, on the upper surface of the tongue, and when this was scraped off numerous red papillæ were seen with bleeding points. The gums bled freely, but nothing abnorinal was observable on the inside of the cheeks, or on the lower surface of the tongue, nor was the mouth sore.

On the 26th the lips were red, and some spots appeared on the lower. On the following day the spots were seen on the inside of the cheeks, frest and larger ones appearing on the tongue, and the mouth becoming 